\title{
MENADEŽMENT PROIZVODA U FUNKCIJI EFIKASNIH TEHNIKA
}

\section{MANAGEMENT OF PRODUCTS OF WORK IN A FUNCTION OF EFFICIENT TECHNIQUES}

\section{Nada Živanović}

Fakultet za poslovno industrijski menadžment Univerziteta „Union“ u Beogradu, Kneza Višeslava 27, 11000 Beograd, Republika Srbija

\section{Vlada Živanović}

Gradska uprava Grada Kragujevca, Trg slobode 3, 34000 Kragujevac, Republika Srbija

\section{Daniela Todorova}

„Todor Kableshov“ University of Transport, 158 Geo Milev Str., Sofia, Bulgaria

\section{Marija Živanović}

Gradska uprava Grada Kragujevca, Trg slobode 3, 34000 Kragujevac, Republika Srbija

\author{
(C) MESTE NGO
}

\section{Sažetak:}

Globalno poslovanje menadžmenta podrazumeva ostvarivanje vizije, misije i strategije kontinualnog učešća proizvoda na tržištu. Praksa kod nas i u svetu govori, da veliki broj proizvoda završi neprimećeno svoj životni vek ne samo na našem već i na inostranom tržištu. Koliko će se dugo određeni proizvodi zadržati na tržištu zavisi od razvoja i primene efikasnih tehnika. U radu su prikazani planski pristup za efikasno produžavanje životnog ciklusa proizvoda, i reinženjering pristup za analizu stanja i potrebno uvođenje inovacija.

\section{Ključne reči:}

menadžment proizvoda, efikasne tehnike, tržište

\section{Abstract: Adresa autora zaduženog za korespodenciju : Nada Živanović 拝”7 profesorkanada@yahoo.com}

Global operations of management involve a vision, mission and strategy of continuous participation of the product on the market. Practice in our country and abroad shows that a large number of products ends up unnoticed not only on our but also on foreign markets. How long a certain products will survive on the market depends on the development and application of effective techniques. The paper displays a planned approach for effective prolongation of life cycle of the products, and reengineering approach for the analysis 
of the situation and the need to introduce innovations.

Keywwords: product management, effective techniques, market

\section{Uvod}

Globalno poslovanje tržišnih kompanija zahteva da se menadžment u potpunosti fokusira na oštra pravila i propise svetskih normi - standarda. Zapravo, međunarodni propisi i pravila poslovanja vode kompanije ka ostvarivanju uspeha na konkurentskom tržištu u dugoročnom periodu. Uspeh zavisi od mnogobrojnih faktora internog i eksternog poslovanja.

Primena i razvoj modernih tehnika poslovanja su jedan od najvažnijih faktora kvalitetnog menadžmenta proizvoda. Pitanje koje se najčešće postavlja u ekonomskom ambijentu vezano je za ciljeve i strategiju proizvodnje proizvoda, i prodaju tog proizvoda.

Kako obezbediti uslove za dugoročno zadržavanje proizvoda na tržištu?

Odgovor bi bio, uspešnom razvojnom strategijom preduzeća i uvažavanjem kvalitetnih metoda i tehnika poslovanja.

\section{Savremene tehnike za proizvodnju proizvoda}

Izrada tržišno prihvatljivog proizvoda, za moderan menadžment je primarni zadatak. Postiže se kada je u kompaniji stvorena dobra osnova za izvoz. Efikasan izvoz zavisi od dobre strategije marketinga.

Podaci govore, da u svetu danas postoji veliki broj proizvoda koji su postali brendovi. Na tržištu naše zemlje postoji samo nekoliko proizvoda savremenog plana, dizajna, imidža, onih proizvoda koji su ostvarili poverenje potrošača. (Žozef, 2004)

Tržišna ekonomija se zasniva na paradigmama, da veći uspeh ostvaruju na tržištu proizvođači razvijenog brenda, iako su oni najčešće skuplji od konkurentskih. Za uspešan menadžment proizvodnje to znači: izgrađena je poslovna menadžerska filozofija kojom proizvođač obezbeđuje kontinualnu proizvodnju, i sigurnu i brzu prodaju. Osnovne postavke takve filozofije koncipirane su na izgrađivanju savremenih pristupa, odnosno tehnika proizvodnje.

\subsection{Tehnika planskog pristupa}

Planski pristup u menadžmentu proizvodnje rezultira zapaženim, uspešnim i razvijenim proizvodima. To podrazumeva uspešnu primenu marketinške filozofije. Plan obuhvata tačno definisanje korelacije između premisa: čuvena marka proizvoda i izvoz. Kod ostvarivanja poznatog proizvoda na tržištu potrebna je osnova za uspešan izvoz.

$\mathrm{Ne}$ može se anoniman proizvod plasirati uspešno niti na našem, a posebno ne na inostranom tržištu. Plan za uspešan izvoz inkorporira poznato i dugogodišnje uspešno poslovanje čiji proizvodi sadrže atrubute: kvalitet, kvantitet, kontinuitet, prihvatljiva cena, i ostvarena dobit preduzeća.

Koliko se dugo određeni proizvodi zadržavaju na tržištu?

Veliki broj proizvoda završi neprimećeno svoj životni vek na tržištu. Posledica toga je, uticaj različitih nepovoljnih faktora koji direktno ili indirektno učestvuju u njegovoj evoluciji. Konstatacija uspešnih ekonomista i ostalih eksperata govori, da je "kratak" životni vek proizvoda na tržištu nedovoljno izučen prostor, i da je to uslov za šire razmišljanje. Takav prostor predstavlja glavni razlog za:

- dalje preispitivanje i analiziranje oblasti menadžmenta proizvoda i proizvodnje u celini i

- preduzimanje inicijativa da se stvari poboljšaju.

Za dugoročno tržišno prepoznavanje i zadržavanje proizvoda potrebno je korišćenje:

- Savremenog znanja iz oblasti tehnike i tehnologije,

- Modernih tehničkih rešenja,

- Većeg nivoa inovativnih rešenja,

- Profitabilnih projekata novih i atraktivnih proizvoda,

- Ideja za brže stvaranje novih proizvoda i dr.

Za nova i profitabilna rešenja potrebna su veća ulaganja kapitala i napora menadžmenta, i ostalih učesnika u proizvodnji. Strateški, to znači, proizvod bi trajao na tržišnoj sceni, prodavao se i unapređivao. To zahteva realizovanje velikog broja 
FBIM Transactions Vol.1 No.1 pp. $66-73$

značajnih i korisnih aktivnosti i to kroz sve faze rasta i razvoja proizvoda. (Porter, 1998)

Put razvoja proizvoda polazi: od ideje do njegove realizacije na tržištu, njegove eksploatacije, pa sve do uklanjanja tog proizvoda sa scene, odnosno uvođenje novog ili usavršavanje istog (diversifikacija), radi produžavanja njegovog životnog ciklusa. Planski pristup je neophodan da bi preduzeće ostvarilo viziju, misiju i strategiju kontinualnog ostvarivanja životnog ciklusa proizvoda.

U tom smislu, planiranje životnog veka proizvoda treba sprovoditi simultano i $u$ interakciji sa funkcijama: projektovanja, marketinga, planiranja, finansija, ekonomike i svim ostalim funkcijama i faktorima internog i eksternog okruženja. Postupak se svodi na sledeće: na osnovu informacija dobijenih istraživanjem tržišta, inženjeri i tehničari, planeri programeri, menadžeri i ostali zaposleni timski planiraju niz aktivnosti koje bi doprinele produžavanju životnog ciklusa proizvoda. Suština je, da se isti nađe $u$ što dužem ciklusu proizvodnog programa i da donosi dohodak preduzeću.

Korist od planskog pristupa je višestruka. Preduzeće reaguje blagovremeno, a ne kada proizvod dostigne kritičnu fazu opstanka na tržištu.

$\mathrm{Na}$ (slici 1) prikazan je životni vek razvoja jednog proizvoda. Životni vek rasta i razvoja nije isti za sve proizvode/usluge, već se razlikuje od proizvoda do proizvoda (Smiljanić, 1992).

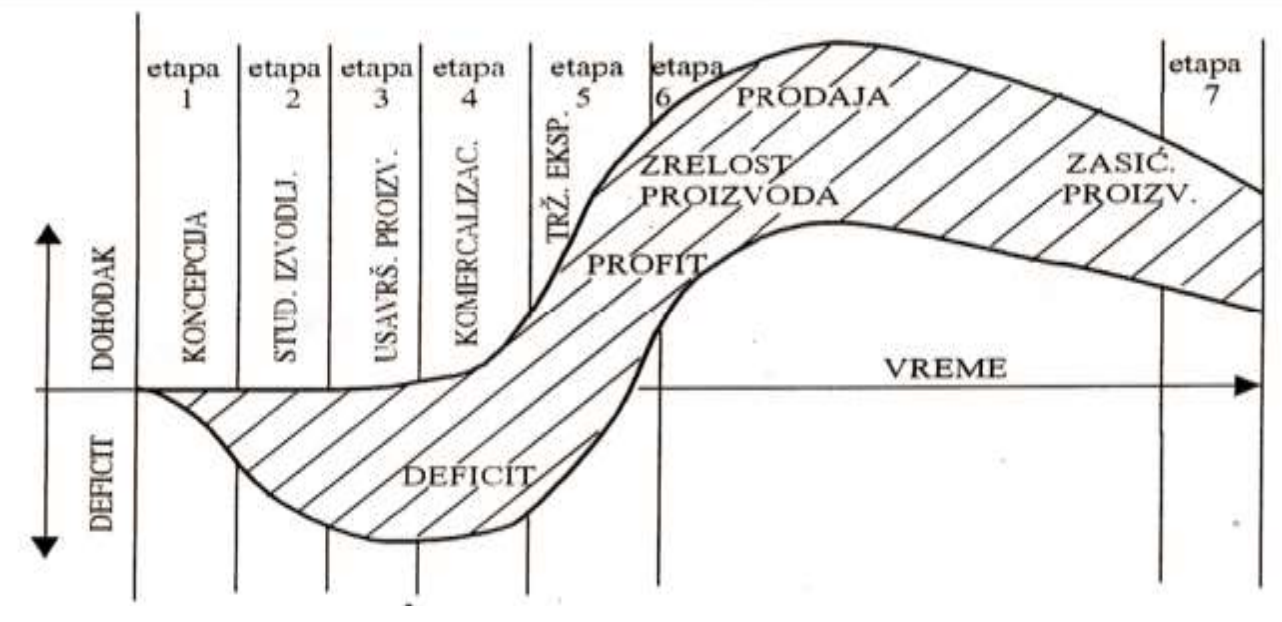

Slika 1. Životni vek razvoja proizvoda (Lukić \& Živanović, 2009)

\subsection{Tehnika reinženjering pristupa}

Razvijene kompanije sve više usmeravaju pažnju na primenu i unapređivanje proizvodnje tehnikom reinženjeringa. Implementacija i razvoj potrebnog reinženjeringa se sprovodi na sledeći način: Menadžment analizira sve aktivnosti u proizvodnom procesu, glavne procese i tzv. pomoćne procese. Prema pokazanim rezultatima tih analiza donosi odluku, u kojoj životnoj fazi je neophodno da se poboljša stanje karakteristika proizvoda i njegovih performansi (Živanović N. , Reinženejring, 2002).

\subsection{Postupak sprovođenja reinženjeringa}

Reinženjering je složena aktivnost koja se prihvata $\mathrm{i}$ sprovodi planski, fundamentalnim promenama, redizajniranjem procesa ili reorganizacijom značajnih aktivnosti.
Posmatra se struktura svake etape razvoja proizvoda pojedinačno, i uočavaju se moguća neskladna rešenja. Rezultati analize beleže se $u$ određene zapise, procedure, karte toka procesa, naloge o preventivnim i korektivnim merama i dr.

Postupak sprovođenja:

- Prvo, strukturira se koncepcija plana. Označava se period formiranja i prihvatanja ideja koje su nastale na bazi istraživanja tržišta.

- Drugo, predviđa se izrada feasibility studije studije izvodljivosti procesa, značajna za tehničko uobličavanje proizvoda, izradu tehničke dokumentacije, ekonomske analize, analize troškova .

- Treće, vrši se poboljšanje faktora kvaliteta svih performansi proizvoda do krajnje perfekcije i usavršavanje proizvoda, izrada prototipa, pristupanje osvajanju proizvodnje nulte serije - 
probne proizvodnje i dr. (Zivanovic, Zivanovic, \& Todorova, 2010)

- Četvrto, komercijalizacija - distribucija novog proizvoda na tržište (neke vrste proizvoda mogu i pre ove faze da ostvare fluktuaciju na tržište).

- Peto, predviđa se, da se desi ono što se planom proizvodnje i marketinškim planom očekuje - tržišna ekspanzija. Planira se vreme penetracije proizvoda, njegovog uspeha i razvoja. $\mathrm{Na}$ osnovu raspoložive moderne tehnologije i mogućnosti njenog daljeg osvajanja i usavršavanja pretpostavlja se, da je moguće prestići konkurenciju.

- Šesto, zrelost proizvoda i nestajanje sa scene. Zasićenje tržišta $s$ jedne strane $i$ ignorisanje proizvoda od strane kupaca $s$ druge strane, stvara probleme kompaniji. Najveći problem su stvaranje neplaniranih zaliha gotovih proizvoda na bazi zastarelih tehnologija ili procesa proizvodnje gde još nije realizovan reinženjering tehnika izvrsnog poslovanja (TQM tehnika) (Živanović, Živanović, \& Lukić, 2011). Da ne bi došlo do gašenja proizvodnje jednog proizvoda, zbog navedenih nedostataka preduzima se redizajn, reorganizacija po potrebi celokupnog proizvodnog sistema, alata, mašina i mašinske opreme, plana diversifikacije proizvoda, i dr.

- Sedmo, zastarelost proizvoda predstavlja ozbiljno stanje proizvoda na tržištu. Značajno je, da se na vreme donesu odluke u menadžmentu o daljem tržišnom poslovanju. Ukoliko je poželjno za tržište treba izvršiti zamenu starog proizvoda novim koji će biti atraktivan za tržištu.

Praksa razvijenih preduzeća koja su usavršila primenu tehnike reinženjeringa je, da se kroz vremensku dimenziju prate ostvareni dohoci (slika 2). Svi proizvodi imaju karakterističnu krivu prometa, zajedničku ili zbirnu krivu, koja predstavlja životni ciklus rasta i razvoja.

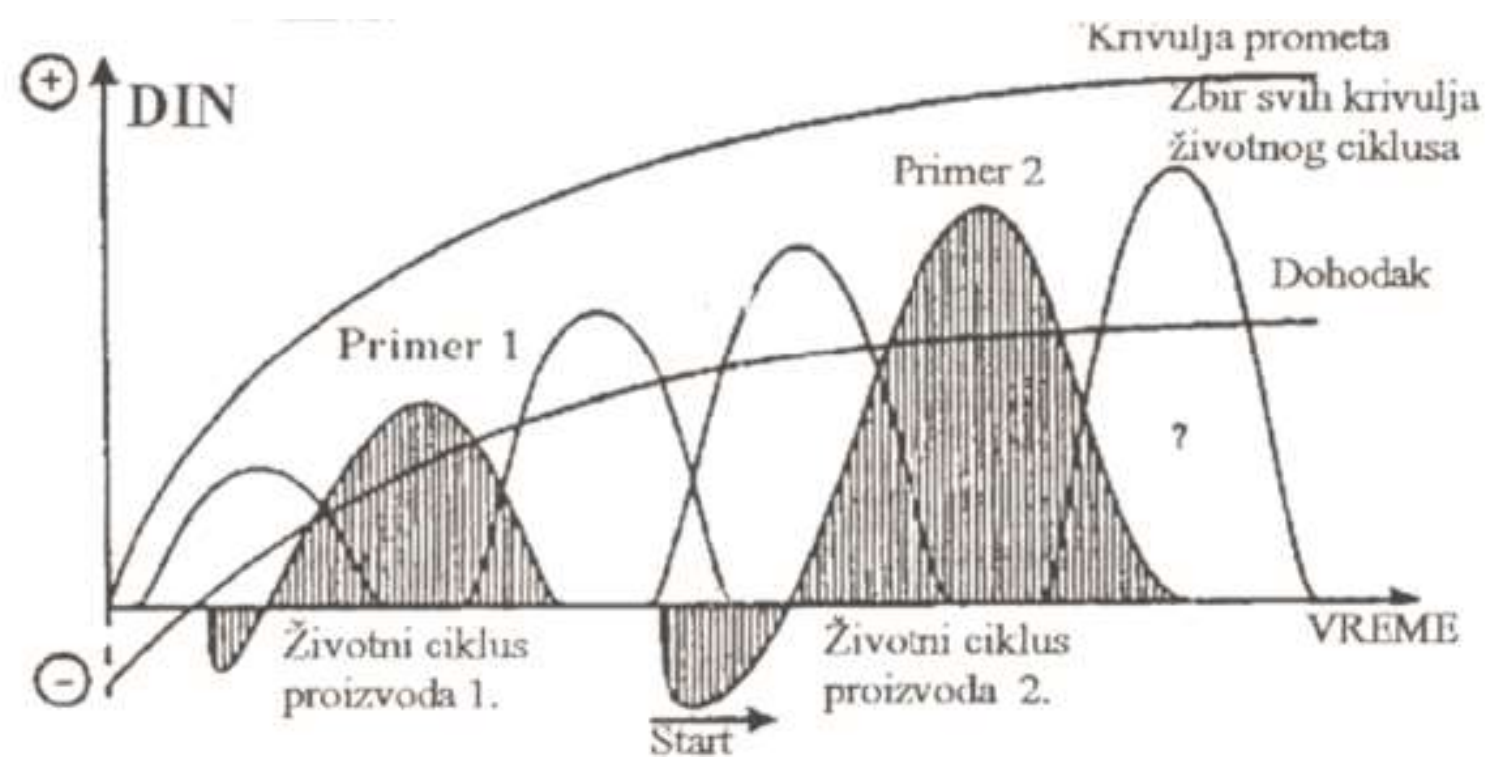

Slika 2. Zbirna kriva dohotka u životnom ciklusu proizvoda (Lukić \& Živanović, 2009)

U većini slučajeva postoji korelacija između planiranog i ostvarenog životnog veka proizvoda. U tom slučaju menadžment treba da primeni efikasne mere kako bi realni životni vek proizvoda približili planiranom. U svom poslovanju treba da se teži ka ostvarenju najboljeg načina prilagođavanja proizvoda zahtevima kupaca.

Za nastale situacije korisno je da se izvode promene reinženjeringom, prevashodno $u$ oblasti nabavke $i$ implementacije novih mašina.
Danas je kod menadžmenta konfuzija i neizvesnost kod izbora između zrelog proizvoda i zrelog tržišta. Zreo proizvod se ne može više poboljšavati, ni fizički ni troškovno. Zrelo tržište je tržište sa statičnim stanjem kada su u pitanju inovacije na tehnologijama i na tržišnim potrebama. Ta stabilnost se manifestuje kroz tri uticaja:

- kroz zastoje u inovacijama proizvoda ili procesa, - kroz zastoje u broju konkurenata koji ulaze ili izlaze sa tržišta i

- kroz zastoje u difuziji proizvoda na celom tržištu. 


\section{Analize vrednosti}

Koncepcija uvođenja potrebnih promena procesom reinženjeringa sadržana je $u$ istraživanju i razmatranju efekata analiza vrednosti. Ova analiza predstavlja skup primene metoda i tehnika još u fazi projektovanja proizvoda pomoću kojih se efikasno utvrđuju potrebni troškovi. U tom poslu cilj je, ostvariti poboljšanja tako što će se (Velč, 2007):

- eliminisati, projektovani ali nepotrebni troškovi na postojećim proizvodima u proizvodnji proizvoda,

- sprečiti već na ulazu u tehnološki proces, sve propuste i greške koje vode preduzeće u nepotrebne troškove (na primer, u proizvodnji, kontrolisanju, ispitivanju, vođenju zapisa i dr.).

Poslovanje menadžmenta na globalnom nivou podrazumeva primenu savremenih metoda i tehnika. Rešavanje problema efikasnog poslovanja menadžmenta procesima, vidi se u pristupu kod donošenja planskih odluka. To znači, donošenje odluka za vreme procesne analize postojećeg stanja u proizvodnim pogonima jedne kompanije.

U nastavku rada će biti prikazani modeli menadžmenta za efikasne i jasne procesne analize. Doprinos se ogleda u preventivnom odlučivanju $i$ spremnosti na promene.

\subsection{Planska odluka menadžmenta procesima}

Donošenje planskih odluka u menadžmentu procesima znači praćenje zahteva i zadovoljstva korisnika svojih proizvoda i usluga na tržištu. Osnova je da se vrednuju informacije u vezi sa zapažanjima kupaca koje se odnose na donešene planske odluke, i na to da li kompanija ispunjava zahteve korisnika.

Pod terminom proces podrazumeva se skup međusobno povezanih resursa $\mathrm{i}$ aktivnosti, koji pretvara ulazne elemente u izlazne elemente

Upravljanje procesima ima za cilj, da se razvija, primenjuje i poboljšava efektivnost tih procesa. $\mathrm{Da}$ bi jedna organizacija, efikasno upravljala procesima treba: 1) da utvrdi i 2) da obavlja menadžment velikim brojem aktivnosti i informacija u celokupnom procesnom sistemu. Aktivnost ili grupa aktivnosti $u$ okviru procesa inkorporiraju veliki broj potrebnih resursa, kojima menadžment omogućava transformaciju ulaznih elemenata $u$ izlazne što se može posmatrate $u$ celini procesom.
Planskim odlukama se želi postići planiranje i razvijanje procesa kojima se upravlja , a koji su potrebni za realizaciju proizvoda. Ovaj plan se usklađuje sa zahtevima svih ostalih procesa, i to: ciljeve sistema kvaliteta i zahteve za proizvod, potrebu za uspostavljanje procesa na osnovu izrađene dokumentacije za sve procese $u$ proizvodnom sistemu preduzeća, i da obezbedi resurse potrebne za dati proizvod.

Prednosti menadžmenta procesa vide se kod rezultata ostvarene veze između pojedinačnih procesa u sistemu procesa, i njihove kombinacije uzajamnog delovanja, interakcijskom strukturom.

Planske odluke koji donosi menadžment je rezultat strategije suštinskog planiranja poslovanja. To je primarna faza procesa menadžmenta. To je važna odgovornost svakog menadžerskog nivoa. Planiranje je aktivnost koja se sprovodi strateški, formulisanjem ciljeva, koordinirana važnim faktorima poslovnog sistema: stilom upravljanja, metodama kontrole. Rezultati procesa planiranja su krajnji cilj donešene planske odluke. Planiranje je proces. Započinje definisanjem ciljeva, kao i sredstava za njihovo ostvarenje.

Za uspešno planiranje potrebna je implementacija, a za dobru implementaciju potrebna je strategija.

Proces planiranja se završava kada se završi merenje efekata preduzetih aktivnosti u ciklusu planiranja. Proces kontrole počinje kada se porede ostvarenja sa ciljevima. Planiranje podrazumeva i stalno praćenje rezultata preduzetih akcija.

Uspeh procesnog menadžmenta (Dracher, 2005) u planiranju se ogleda u realizaciji sledećih aktivnosti:

- dobro postavljanje dijagnostike stanja,

- ispravno definisanje ciljeva, odnosno donošenje odluke o tome šta se želi ostvariti u funkcijama ili u celokupnom preduzeću,

- utvrđivanje faktora koje treba iskoristiti, kao i faktora koje treba izbegavati,

- donošenje odluka menadžera o izboru najbolje alternative,

- merenje efekata preduzetih aktivnosti za ostvarivanje ciljeva i dr.

\subsection{Tim kompetentnih menadžera}

Za donošenje planske odluke važan je tim. Tim vodi, organizuje, planira posao, realizuje planove. Glavni posao menadžmenta je da oko sebe okupi kvalitetan 
tim u kojem će svaki član razmišljati o tome kako da se donese dobra planska odluka koja će da unapredi posao.

Cilj svakog uspešnog menadžmenta je stvaranje i razvijanje kompetencija. Suština kompetentnosti je stalno izražavanje želje i shvatanja, izučavanja procesa, kolektivnog učenja u preduzeću.

Ključno je, jezgro kompetentnosti. To je integrisani set sposobnosti, veština, visprenosti, tehnologija u potrebnoj oblasti i njene primene $u$ toj oblasti. Cilj je, da se u preduzeću stvore planovi i novi putevi koji vode uspehu i daju šansu preduzeću da uspe na tržištu. U osnovi to je alat za ispitivanje stanja poslovanja i korišćenja unutrašnjih snaga preduzeća. Smisao je postignut ukoliko to jezgro dovodi do novih planova i novih proizvoda, ili novih tržišta. To znači da se ispunjavaju specifične potrebe kupaca.

Kompetencije su pogonska snaga za razvoj novih planova, donošenja odluka, razvoj novih poslova $i$ dr. To je skup sposobnosti koje preduzeću daju šanse za atraktivne proizvode.

Osnovni koraci za definisanje jezgra kompetentnosti u jednom preduzeću su:

- Indentifikovanje i razlaganje veština i know-how $u$ onom delu gde su planske odluke veoma uspešne i gde je preduzeće uspešno.

- utvrđivanje prisustva know-how u okviru pojedine funkcije ili u celokupnom preduzeću.

- Analiza i istraživanje postignutog uspeha preduzeća (većeg ili manjeg) u odnosu na konkurenciju.

- Utvrđivanje validnih i značajnih parametara konkurentske prednosti.

- Utvrđivanje trajnosti konkurentske prednosti u smislu spremnosti za ulaganja preduzeća u kompetencije

- Utvrđivanje ključnih promena u preduzeću koje su u funkciji stalnog ispoljavanja sposobnosti preduzeća za razvojem kompetencija

- Dati odgovore na pitanja:

1. koje kompetencije će zastariti i ne treba im pridavati veću pažnju?

2. koje treba održavati i poboljšavati?

3. koje nove kompetencije treba razvijati?

\subsection{Analiza planskih odluka}

Razvoj i unapređivanje poslovne strategije vezane za ciljeve upravljanja procesima na bazi donošenja planskih odluka i na bazi kompetencija menažmenta, je od posebnog značaja za realizaciju započetog ciklusa: planiranja i donošenja odluka o efikasnim aktivnostima procesnog menadžment. Cilj je, da se ostvari:

- visok kvalitet donešenih odluka,

- niske cene i

- da se radni zadaci i aktivnosti ostvaruju tačno na vreme (just-in-time).

Navedene karakteristike dobijene analizom doprinose bržem i lakšem upoznavanju menadžmenta, inženjera, planera, programera $\mathrm{i}$ projektanata sa koncepcijom aktuelnih zahteva novih tehnologija.

Koncepcija savremene tehnike i tehnologije je koncipirana tako da se njenom primenom obezbeđuju stalna poboljšanja.

Zato je plansko predviđanje za donošenje najvažnijih odluka determinisano potrebama stalnog:

- projektovanja savremene tehnoloških i menadžerskih procesa sa povećanom fleksibilnošću,

- postizanja visokog stepena fleksibilnosti,

- povećanja motivisanosti projektanata, planera ka usmeravanju na tržište

- povećanja ekonomskih efekata tog plana,

- povećanja odgovornosti menadžmenta prilikom planiranja.

\section{ZAKLJUČAK}

$U$ tehnici $\mathrm{i}$ tehnologiji značajno mesto zauzima inkorporiranje standarda $u$ donošenju planskih odluka, za realizaciju postavljenih ciljeva i strategije upravljanja procesima na nivou organizacijske strukture. To olakšava menadžmentu efikasnije sagledavanje problema odnosno, rešavanje potrebnih poboljšanja stanja odvijanja procesa.

Posebno je u menadžmentu procesima značajna primena standardizacije je u procesima planiranja $\mathrm{i}$ projektovanja proizvoda. Standardizacija kao naučna i pragmatična disciplina sadrži jednobrazna rešenja problema koji se ponavljaju, a naročito ima za cilj da se na njenim postavkama, pravilima i zahtevima poveća ekonomičnost proizvodnje i poslovanja. Korišćenje standarda, propisa, pravila, zakonitosti, normi, preporuka i sl. ima važnu ulogu u 


menadžmentu procesima. Bez primene
standardizacije proizvodi se ne mogu prodavati na svetskom tržištu. Najčešće korišćeni standardi su: međunarodni standardi (ISO)standardi zemalja EEZ, nacionalni standardi (državni, npr. GOST, DIN, SR, SQS, AQA i dr.), preduzetnički (interni) i drugi (Živanović N. , 2000).

Navedeni standardi i navedene kompetencije omogućavaju unapređenje planiranja tehnologije za realizaciju proizvoda, tehnologije procesa, tehnologije rada i organizacije i sl. Pružaju širok opseg uvođenja stalnih poboljšanja prema međunarodnim propisima poslovanja, odnosno omogućavaju da se ugradi veliki obim različitog znanja u kome je sadržan veliki broj optimalnih rešenja. Time se menadžmentu otvara prostor za bržu i efikasniju strategiju penetracije proizvoda na tržište i spremnost za konkurentsku utakmicu.

Da bi preduzeće bilo konkurentno na tržištu, treba da vidi sopstveni cilj nakon sprovođenja potrebnih poboljšanja. Suština je, da primenom datih pristupa usmerenih ka poboljšanjima brže se generišu samostalna tehnička rešenja u celini.

Činjenica je, da su mnoga preduzeća zavisna od inostranih znanja u odnosu na tehničku i tehnološku opremljenost za proizvodnju, sredstava za rad i drugih faktora sistema kvaliteta proizvoda. Razvoj kvaliteta proizvodnje se odnosi kako na jednostavne, tako i na složene procese projektovanja, izrade, kontrole, servisiranja i sl.

To zahteva sprovođenje potrebnih adaptacija poboljšanja procesa $u$ domenu tehnike i tehnologije planskim i reinženjering pristupom na bazi: edukacije kadrova za savremene tehnike, većeg ulaganja u skupu, složenu i raznovrsnu opremu, većeg ulaganja u ujednačavanje tehnoloških nivoa, postizanja potrebnog kapaciteta, fleksibilnosti i racionalnosti mašinskog parka, poboljšanja i povećanja ukupnih znanja za projektovanje i realizaciju i potrebne investicije za razvojne projekte.

Pod savremenim, fleksibilnim tehnološkim sistemima podrazumeva se oprema - sredstva za rad, koji su povezani upravljačkim sistemima, kao i sistemima za tokove materijala, u cilju ostvarenja automatske proizvodnje delova.

Osnovne karakteristike fleksibilnih sistema su: sposobnost promena redosleda operacija pomoću upravljačkih programa, proizvodnja različitih proizvoda malih serija, zahtev za potrebno ulaganje velikih investicija naročito u slučaju promene asortimana proizvodnje, i dr.

Napred navedeno je, osnova za ostvarivanje strategijskog cilja menadžmenta, inženjera i projektanata na ostvarivanju forme upravljanja koncepcijama aktuelnih i novih tehnologija.

Sama koncepcija savremene tehnike i tehnologije je koncipirana tako, da tokom njene primene uvek se obezbeđuju poboljšanja, koja se konkretno mogu ostvariti kroz plansko predviđanje najvažnijih aktivnosti, i to kroz: projektovanje savremenih tehnoloških procesa sa povećanom fleksibilnošću, postizanje optimalnog stepena fleksibilnosti, motivisanost projektanata usmerena ka tržištu i ekonomskim efektima tog plana, povećanje odgovornost projektanata prilikom projektovanja i uspostavljanja optimalnih nivoa fleksibilnosti tehnoloških procesa (opreme, sistema).

\section{Citirani radovi}

Dracher, P. (2005). Upravljanje u novom društvu. Novi Sad: Adižes.

Lukić, S., \& Živanović, N. (2009). Poslovni reinženjering. Banja Luka: Panevropski univerzitet "Apeiron".

Porter. (1998). Competitive Advantage. In Doz, \& Hamel, Alliance Advantage: The Art of Creating Value Through

Partnering (p. 66). Boston, MA:: Harvard Business School Press.

Smiljanić, S. (1992). Organizovanje industrijskih preduzeća. Kragujevac: ESKOD d.d.

Velč, D. (2007). Veština pobeđivanja. Novi Sad: Asee.

Živanović, N. (2000). Kako do Tqm-a? Beograd: Zadužbina Andrejević.

Živanović, N. (2002). Reinženejring. Novi Sad: Fakultet za preduzetni menadžment. 
Živanović, N., Živanović, V., \& Lukić, S. (2011). Affirmation of integrated quality management system in medium enterprises. International scientific conference SMEPP. Novi Pazar: International university of Faculty for management in traffic and communication Novi Pazar.

Zivanovic, N., Zivanovic, V., \& Todorova, D. (2010). Reengineering of business processes - strategy of turning points. Academic journal Mechanics Transport Communications,(2).

Žozef, I. (2004). Kako se pravi robna marka. Ekonometar, 7.

Datum prve prijave:

18.09.2012.

Datum prijema ispravke članka:

29.10.2012.

Datum prihvatanja članka:

16.11.2012.

\section{Kako citirati ovaj rad?}

Style - APA Sixth Edition:

Živanović, N., Živanović, V., Todorova, D., \& Živanović., M. (2013, 01 15). Menadžment proizvoda u funkciji efikasnih tehnika. (Z. Čekerevac, Ed.) FBIM Transactions, 1(1), 66-73. Retrieved from www.meste.org/fbim/FBIM 1 2013/ 07.pdf. doi: 10.12709/fbim.01.01.01.07

Style - Chicago Fifteenth Edition:

Živanović, Nada, Vlada Živanović, Daniela Todorova, and Marija Živanović. "Menadžment proizvoda u funkciji efikasnih tehnika." Edited by Zoran Čekerevac. FBIM Transactions (MESTE NVO) 1, no. 1 (01 2013): 66-73.

Style - GOST Name Sort:

Živanović Nada [et al.] Menadžment proizvoda u funkciji efikasnih tehnika [Journal] = Menadežment proizvoda u funkciji efikasnih tehnika // FBIM Transactions / ed. Čekerevac Zoran. - Beograd : MESTE NVO, 01 15, 2013. - 1 : Vol. 1. - pp. 66-73.

Style - Harvard Anglia:

Živanović, N., Živanović, V., Todorova, D. \& Živanović., M., 2013. Menadžment proizvoda u funkciji efikasnih tehnika. FBIM Transactions, 15 01, 1(1), pp. 66-73.

Style - ISO 690 Numerical Reference:

Menadžment proizvoda u funkciji efikasnih tehnika. Živanović, Nada, et al. [ed.] Zoran Čekerevac. 1, Beograd : MESTE NVO, 01 15, 2013, FBIM Transactions, Vol. 1, pp. 66-73. 